\title{
Orbital apex syndrome associated with herpes zoster ophthalmicus
}

This article was published in the following Dove Press journal:

Clinical Ophthalmology

8 November 2011

Number of times this article has been viewed

\section{Takuji Kurimoto' \\ Masahiro Tonari' \\ Norihiko Ishizaki' \\ Mitsuhiro Monta ${ }^{2}$ \\ Saori Hirata ${ }^{2}$ \\ Hidehiro Oku' \\ Jun Sugasawa' \\ Tsunehiko Ikeda' \\ 'Department of Ophthalmology, Osaka Medical College, ${ }^{2}$ Department of Ophthalmology, Shitennoji Hospital, Osaka, Japan}

Correspondence: Takuji Kurimoto Department of Ophthalmology, Osaka Medical College, 2-7 Daigaku-machi, Takatsuki, Osaka 569-8686, Japan

Tel $+8 \mid 72683$ I 22I

Fax $+8|7268| 8195$

Email kuritakul20II20I@yahoo.co.jp
Abstract: We report our findings for a patient with orbital apex syndrome associated with herpes zoster ophthalmicus. Our patient was initially admitted to a neighborhood hospital because of nausea and loss of appetite of 10 days' duration. The day after hospitalization, she developed skin vesicles along the first division of the trigeminal nerve, with severe lid swelling and conjunctival injection. On suspicion of meningoencephalitis caused by varicella zoster virus, antiviral therapy with vidarabine and betamethasone was started. Seventeen days later, complete ptosis and ophthalmoplegia developed in the right eye. The light reflex in the right eye was absent and anisocoria was present, with the right pupil larger than the left. Fat-suppressed enhanced T1-weighted magnetic resonance images showed high intensity areas in the muscle cone, cavernous sinus, and orbital optic nerve sheath. Our patient was diagnosed with orbital apex syndrome, and because of skin vesicles in the first division of the trigeminal nerve, the orbital apex syndrome was considered to be caused by herpes zoster ophthalmicus. After the patient was transferred to our hospital, prednisolone $60 \mathrm{mg}$ and vidarabine antiviral therapy was started, and fever and headaches disappeared five days later. The ophthalmoplegia and optic neuritis, but not the anisocoria, gradually resolved during tapering of oral therapy. From the clinical findings and course, the cause of the orbital apex syndrome was most likely invasion of the orbital apex and cavernous sinus by the herpes virus through the trigeminal nerve ganglia. Keywords: varicella zoster virus, orbital apex syndrome, herpes zoster ophthalmicus, complete ophthalmoplegia

\section{Introduction}

Orbital apex syndrome is a condition in which the oculomotor nerve, trochlear nerve, abducens nerve, and ophthalmic branch of the trigeminal nerve are damaged. These alterations are generally associated with optic nerve dysfunction. Orbital apex syndrome can be caused by a variety of inflammatory, infectious, neoplastic, iatrogenic/ traumatic, and vascular conditions. ${ }^{1}$ We present our findings in a patient with orbital apex syndrome associated with herpes zoster ophthalmicus. Magnetic resonance imaging (MRI) showed inflammatory changes that extended to the cavernous sinus and orbital apex. Treatment with intravenous prednisolone $60 \mathrm{mg}$ followed by tapering and vidarabine antiviral therapy markedly improved the extraocular palsies and optic nerve dysfunction. These changes normalized after treatment, which indicated the pathogenesis of the case.

\section{Case report}

An 81-year-old woman attended a neighborhood hospital because of nausea and loss of appetite of 10 days' duration. The internist found that the patient was severely 
dehydrated, and she was admitted to our hospital on the same day. On the following day, a rash developed along the first division of the trigeminal nerve, and she had a fever of about $38^{\circ} \mathrm{C}$. No neck stiffness was reported.

Examination of the cerebrospinal fluid showed 90 cells $/ \mu \mathrm{L}$, with a predominance of lymphocytes and a protein level of $75 \mathrm{mg} / \mathrm{dL}$. IgG for varicella zoster virus in the cerebrospinal fluid was positive on enzyme immunoassay and the unit value was 12.8 , but IgM for varicella zoster virus was negative. MRI and computed tomographic images of the head showed no signs of meningitis or edematous changes in the cerebral parenchyma.

Herpetic encephalitis induced by varicella zoster virus was suspected from the clinical findings, so intravenous vidarabine $600 \mathrm{mg} /$ day was initiated in combination with sulbactam + defoperazone sodium and betamethasone $4 \mathrm{mg}$. The patient still had severe dehydration due to insufficient fluid intake, and her serum creatinine was elevated to $0.96 \mathrm{mg} / \mathrm{dL}$ (normal range $0.47-0.79 \mathrm{mg} / \mathrm{dL}$ ). Thus, we did not use acyclovir systemically because it could have worsened her renal dysfunction. However, the headache and orbital pain worsened. On day 7 of her hospital stay, there was a reduction of the corneal reflex, and herpes keratoconjunctivitis was diagnosed. Treatment with antiviral ointment, acyclovir, and betamethasone eye drops were started. On day 17 of the hospital day, she developed ptosis and total ophthalmoplegia in the right eye (Figure 1A). The pupillary diameters were $4.5 \mathrm{~mm} \mathrm{OD}$ and $2.5 \mathrm{~mm} \mathrm{OS}$, and the light reflex in the right eye was absent (Figure 1B). The anisocoria was pronounced under ordinary room light. Best-corrected visual acuity was
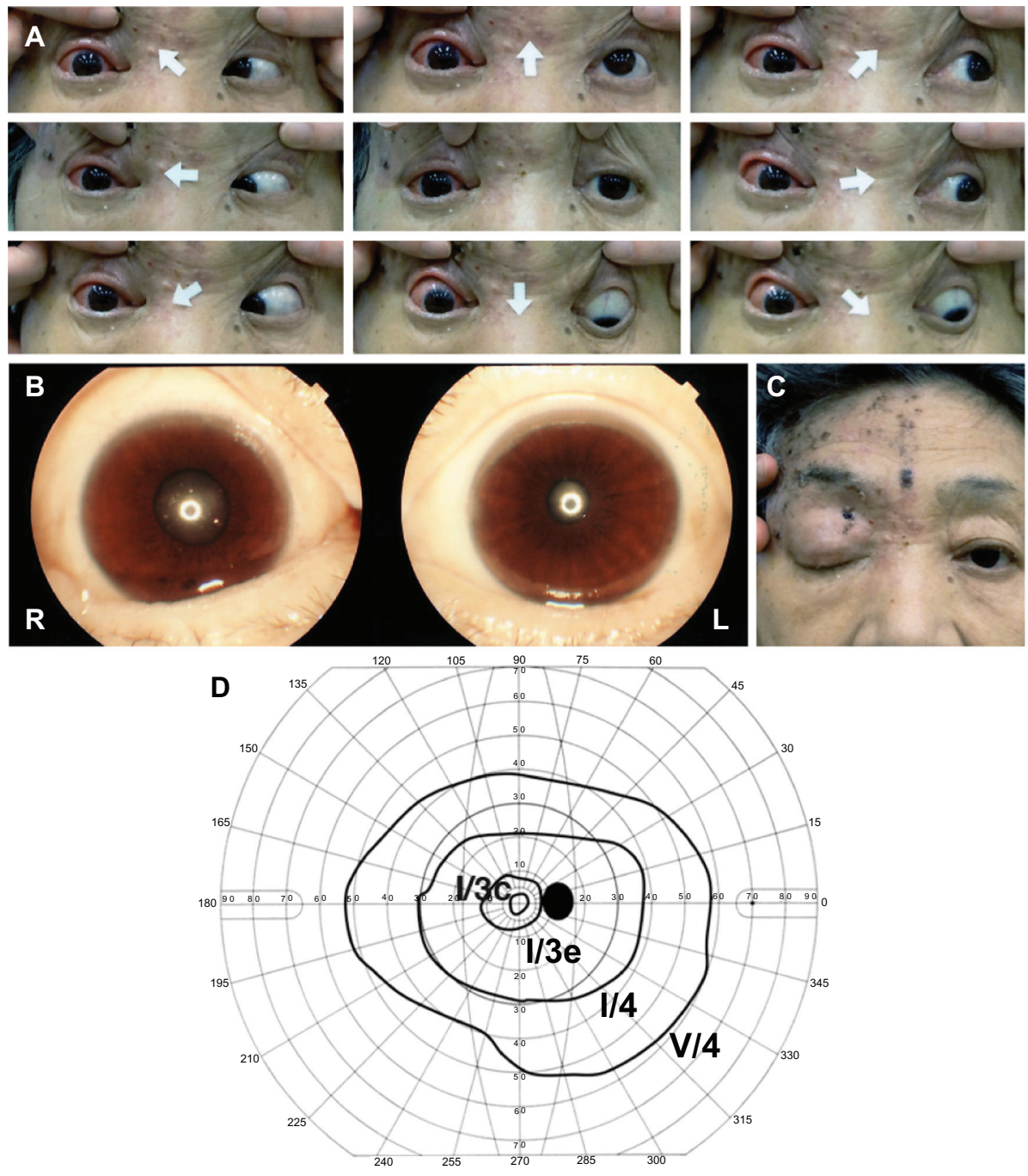

Figure I Photographs of eye positions in all directions, and the pupils and face of our patient before treatment. (A) Photographs of eye positions in all directions. Complete ophthalmoplegia and ptosis can be seen on the right side. (B) Photographs of pupils under standard room lighting. Anisocoria can be seen and the right pupil is dilated. The light reflex is absent. (C) Photograph of the face. Mixed vesicular and crusted eruptions can be seen along the first division of the trigeminal nerve. Complete ptosis is present in the right eye. (D) Goldmann kinetic perimetry. Slight constriction of the visual field was detected in the right eye. 
$0.5 \mathrm{OD}$ and 1.0 OS. Central critical fusion frequency was $29 \mathrm{~Hz}$ OD and $31 \mathrm{~Hz}$ OS, and the intraocular pressures were $17 \mathrm{mmHg}$ OD and $14 \mathrm{mmHg}$ OS. Goldmann kinetic perimetry showed a slight constriction of the central visual field in the right eye (Figure 1D). Enhanced T1-weighted MRI showed enhancement of the optic nerve and orbital apex (Figure 2A and B).

From these clinical findings, ie, orbital inflammation affecting the orbital apex and IgG for varicella zoster virus in the cerebrospinal fluid, the patient was diagnosed with orbital apex syndrome due to varicella zoster virus reactivation. ${ }^{2}$ After the patient was transferred to our hospital for further treatment, intravenous prednisolone $60 \mathrm{mg} /$ day was started in combination with vidarabine $600 \mathrm{mg} /$ day. The ocular symptoms improved soon after initiation of steroid therapy. The limitation of adduction and supraduction improved from day 1 after initiation of therapy. Repeated MRI showed a decrease in enhancement of the right optic nerve and the tissues around the orbital apex (Figure 2C and D). Levels of cells and proteins in the cerebrospinal fluid were also decreased. The ptosis had recovered by about 11 weeks after the start of treatment. The right palpebral fissure was $9 \mathrm{~mm}$ and levator function was $10 \mathrm{~mm}$. Twelve weeks after onset, diplopia at the primary position disappeared, and the best-corrected visual acuity in the right eye improved to 1.0 (Figure 3). Twenty weeks after onset, eye movements were almost completely recovered, except for abduction (Figure 4). However, the anisocoria still remained, despite the patient taking prednisolone $15 \mathrm{mg}$ /day.

\section{Discussion}

Herpes zoster ophthalmicus can be triggered by reactivation of varicella zoster virus that is dormant in the trigeminal
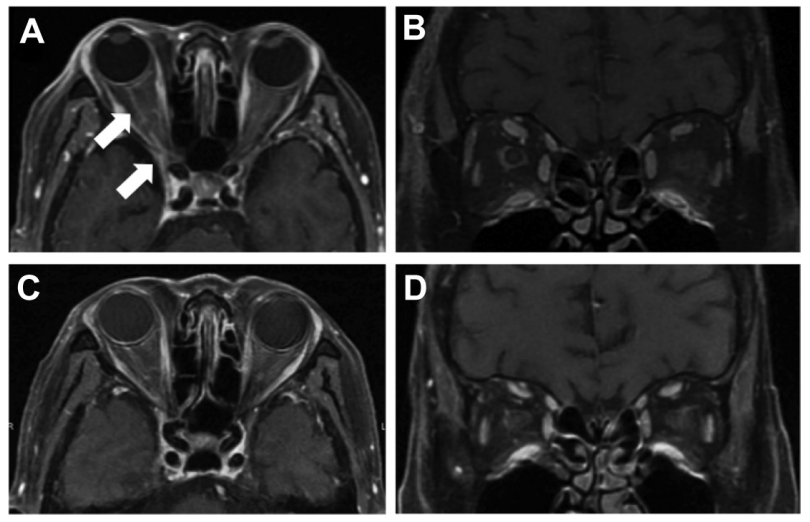

Figure 2 Enhanced fat-suppressed $\mathrm{Tl}$-weighted magnetic resonance images (A and $\mathbf{B}$ ) before steroid therapy. (C and $\mathbf{D})$ after intravenous prednisolone. (A and $\mathbf{C}$ ) are horizontal sections. (B and $\mathbf{D})$ rare coronal sections. Enhancement of the optic nerve sheath and orbital apex can be seen before treatment (arrows). nerve ganglia. Reactivation of varicella zoster virus can be triggered by aging, an immunocompromised host, trauma, surgery, iatrogenic immunosuppression, tuberculosis, syphilis, and radiation therapy. Half of herpes zoster ophthalmicus cases have ocular complications, including blepharitis, keratoconjunctivitis, iritis, scleritis, and acute retinal necrosis. ${ }^{3}$ Neurological complications, such as ophthalmoplegia and optic neuritis, are rare, but are responsive to antiviral or steroid treatment. Ophthalmoplegia was found in 3.5\%-10.1\% of two large herpes zoster ophthalmicus series. ${ }^{3,4}$ Among the cases with extraocular nerve palsies, oculomotor nerve palsy is the most frequent and abducens nerve palsy the second most frequent. 5,6

Several cases of orbital apex syndrome have been reported in association with more severe herpes zoster ophthalmicus. ${ }^{7-12}$ Shirato et al reported a 71-year-old man who developed orbital apex syndrome 12 days after onset of herpes zoster ophthalmicus. ${ }^{7}$ T1-weighted, gadoliniumenhanced MRI showed diffuse enhancement of the orbital fat, ocular muscles, and optic nerve on the right side. They used systemic prednisolone $30 \mathrm{mg}$ followed by tapering. Five months after the onset of herpes zoster ophthalmicus, the extraocular palsies and ptosis were slightly improved, but there was no improvement in visual acuity. Kattah and Kennerdell reported two cases of orbital apex syndrome associated with herpes zoster ophthalmicus. ${ }^{8}$ Both cases developed extraocular palsies and optic nerve dysfunction one and five days after onset of rash. After oral prednisolone $80 \mathrm{mg}$, one of the patients recovered fully from the neurological complications, and the other patient had an improvement in ophthalmoplegia and optic neuritis, but the left eye progressed to endophthalmitis followed by corneal perforation.

Krasnianski et al reported a case of orbital apex syndrome with complete ophthalmoplegia due to orbital myositis and optic neuritis two days after the onset of herpes zoster ophthalmicus. ${ }^{10}$ The case was a 67 -year-old woman who was treated with acyclovir $750 \mathrm{mg}$ for 10 days with prednisolone $100 \mathrm{mg}$ intravenously for three days, and then the prednisolone was tapered. MRI with gadolinium enhancement showed marked thickening of all the external ocular muscles and optic nerve sheath on the right side. Four weeks later, the extraocular muscle palsies and optic neuritis recovered almost completely.

Bourke and Pyle reported a 63-year-old woman with herpes zoster ophthalmicus who developed complete ptosis, total ophthalmoplegia, and loss of visual acuity 10 days after the rash developed. ${ }^{11}$ Treatment consisted of intravenous 


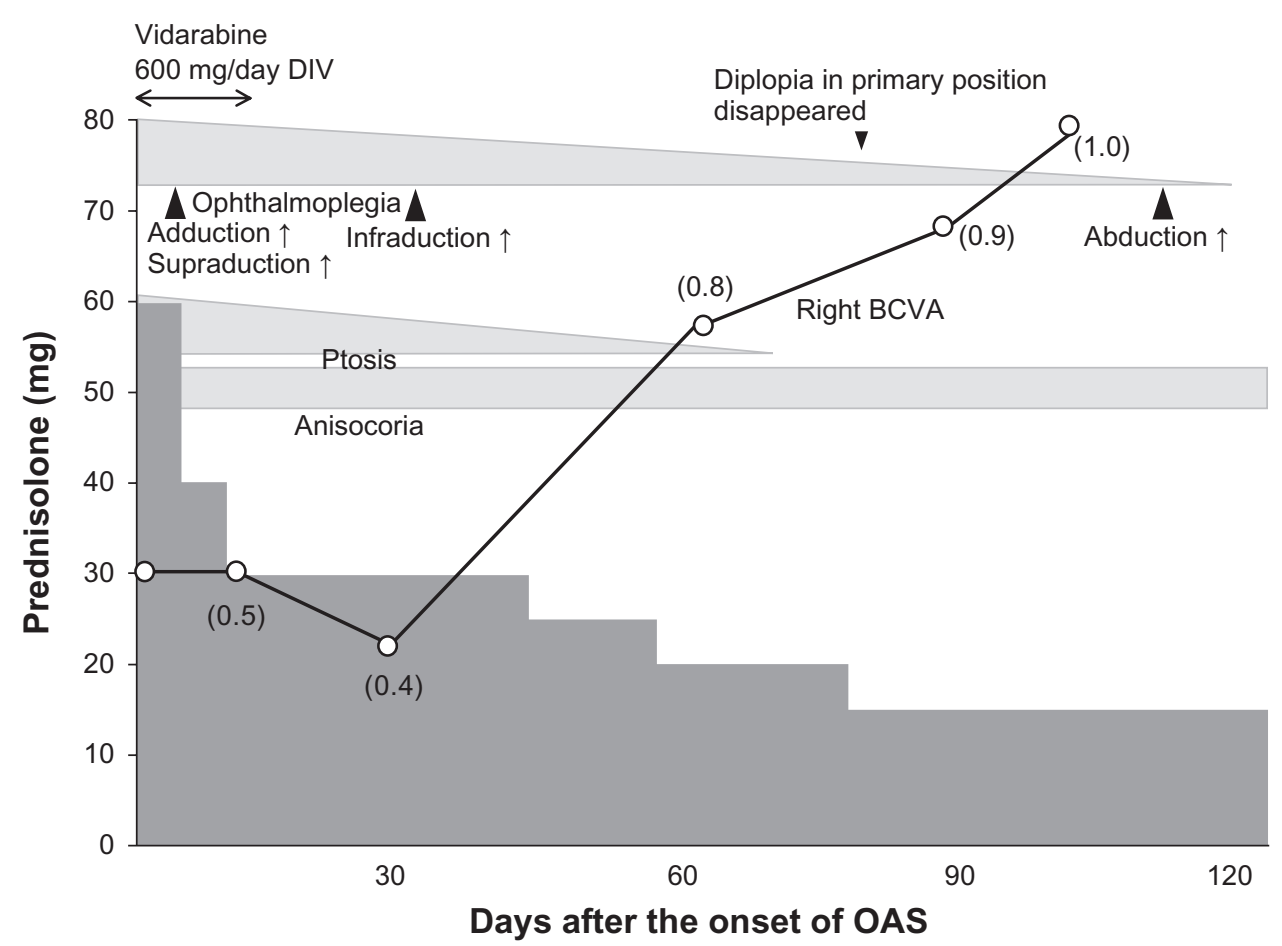

Figure 3 Time course of ocular symptoms and signs after onset of orbital apex syndrome. After onset, the amount of steroid was increased from betamethasone $4 \mathrm{mg}$, and the converted amount of prednisolone was $26-60 \mathrm{mg}$. Ocular movement, visual acuity, and ptosis gradually improved thereafter. Vidarabine was also given for 12 days after the onset of orbital apex syndrome.

Abbreviations: OAS, orbital apex syndrome; DIV, intravenous injection by drip; BCVA, best-corrected visual acuity.

methylprednisolone $500 \mathrm{mg} /$ day for three days, followed by a two-week course of oral prednisolone reducing by $80 \mathrm{mg}$ /day. Oral acyclovir $800 \mathrm{mg}$ every four hours was also used. The ocular movements slowly improved. The day following initiation of therapy, supraduction, infraduction, and incyclotorsion were slightly improved. Visual acuity also

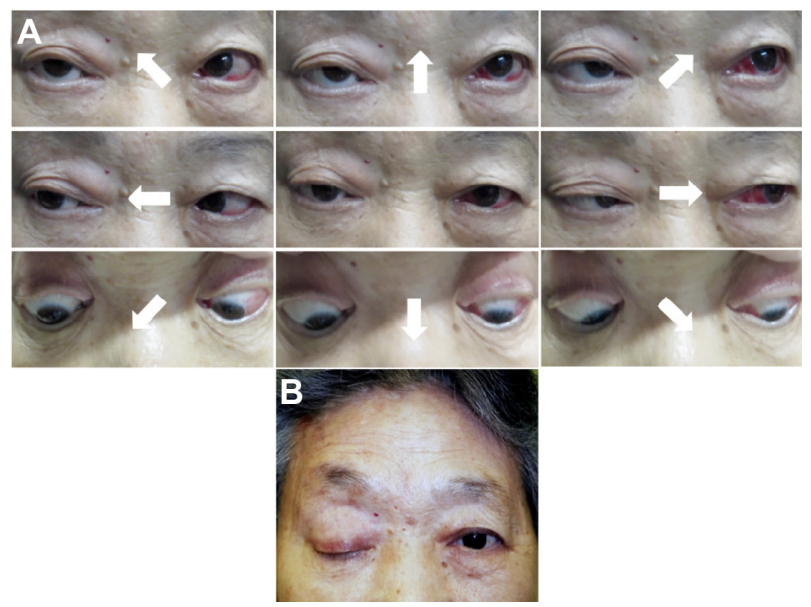

Figure 4 Photographs of eye positions in all directions five months after initiation of therapy. (A) Most ocular movements are markedly improved, except for abduction. Subconjunctival hemorrhage is present in the left eye. (B) Photograph of face one month after initiation of therapy. The skin lesions are almost resolved but ptosis remains. increased from finger counting to $6 / 24$ on the next day, and further improved to $6 / 18$ soon thereafter. At one year after onset, visual symptoms were completely resolved.

Dhingra et $\mathrm{al}^{9}$ reported a case of orbital apex syndrome associated with herpes zoster ophthalmicus and multiple myeloma. The signs and symptoms of herpes zoster ophthalmicus developed after the patient had completed chemotherapy. Although systemic acyclovir and prednisolone $30 \mathrm{mg}$ slightly improved the visual acuity and disturbances of eye movements, the ptosis, anisocoria, and partial ophthalmoplegia did not improve. Saxena et $\mathrm{al}^{12}$ also reported a case of human immunodeficiency virus associated with herpes zoster ophthalmicus. A 29-year-old woman developed severe anterior uveitis, optic neuritis, complete ptosis, and ophthalmoplegia due to myositis 14 days after the onset of a facial rash. Serological testing was positive for human immunodeficiency virus. Highly active antiretroviral therapy and oral acyclovir $800 \mathrm{mg}$ five times a day were started. Five days later, oral prednisolone $1 \mathrm{mg} / \mathrm{kg} /$ day was combined with highly active antiretroviral therapy and acyclovir therapy. By the end of four weeks, visual acuity and extraocular motility were markedly improved.

In most of the earlier reports, and in our patient, orbital apex syndrome developed within 14 days of onset of herpes 
zoster ophthalmicus and was relatively responsive to steroid therapy, but may need more than $60 \mathrm{mg}$ of prednisolone. The outcomes of visual function were good, although the duration of treatment may need to be from four weeks to one year.

Sanjay et al summarized the clinical characteristics and course of 20 well documented cases of herpes zoster ophthalmicus presenting with complete ophthalmoplegia. ${ }^{13}$ Herpes zoster ophthalmicus preceded the ophthalmoplegia as orbital apex syndrome by a mean interval of 9.5 days. Sixty-five percent of these cases recovered completely or partially after antiviral and steroid therapy, although anisocoria remained in most cases, as in our patient. In consideration of our case and the earlier reports, combined antiviral and steroid therapy should be effective in cases of orbital apex syndrome if the steroid therapy is used for at least four months.

The pathological mechanism for ophthalmoplegia in cases of herpes zoster ophthalmicus has not been determined. Histopathological studies have demonstrated significant perivascular and perineural inflammation of the ocular tissues, including the optic nerve, cavernous sinus, superior orbital fissure, and retina. ${ }^{14}$ Earlier histological studies on autopsy specimens have suggested two possible pathological mechanisms, ie, reactivation of varicella zoster virus in the trigeminal ganglion, which then invades the cavernous sinus and superior orbital fissure, ${ }^{5}$ and a second mechanism might be lymphocytic infiltration of the affected nerves by sensory offshoots of the trigeminal nerves to all the motor nerves of the eye. ${ }^{15}$ Naumann et al showed that inflammatory cells infiltrated the orbital apex along the long posterior ciliary vessels and nerves in 21 enucleated eyes affected by herpes zoster ophthalmicus, indicating that the neuropathy arises from an occlusive vasculitis. ${ }^{16}$ Thus, the ophthalmoplegia and optic neuritis are suggested to be due to direct invasion by varicella zoster virus or by an inflammatory reaction and occlusive vasculitis after virus invasion. Lexa et al reported a case of herpes zoster ophthalmicus with optic neuritis, total ophthalmoplegia, and cerebellar manifestations. ${ }^{14}$ Enhanced MRI showed enhancement around the optic nerve sheath, which corresponded with the post mortem findings of invasion of inflammatory cells into the sheath of the optic nerve and ischemic changes in the optic nerve axons.

Cases of herpes zoster ophthalmicus with optic neuritis have been reported, and MRI and computed tomography show direct spread of granulomatous inflammation into the orbital apex. ${ }^{8,11}$ Immunohistological examination of an autopsy specimen in a case of human immunodeficiency virus infection showed direct invasion of varicella zoster virus into the retina and optic nerve. ${ }^{17}$
Our patient responded well to steroids and antiviral therapy, although the time needed to achieve significant resolution was more than five months. However, treatment for herpetic encephalopathy, with which our patient was initially diagnosed, might not have been long enough to improve symptoms. MRI findings showing enhancement of the optic nerve might reflect a direct inflammatory reaction rather than occlusive vasculitis.

In conclusion, herpes zoster ophthalmicus is a relatively common disease in clinical ophthalmological practice, but is rarely accompanied by neurological complications. Orbital apex syndrome should be considered among the more severe ocular complications of herpes zoster ophthalmicus. If combined antiviral and steroid therapy is initiated early, it can be expected that visual dysfunction will recover. Therefore, ophthalmologists should be careful not to miss the neurological complications, and be especially vigilant during the 14 days after onset of herpes zoster ophthalmicus.

\section{Acknowledgment}

We thank Professor Duco Hamasaki, Bascom Palmer Eye Institute, University of Miami School of Medicine, for editing this manuscript.

\section{Disclosure}

The authors report no conflicts of interest in this work.

\section{References}

1. Yeh S, Foroozan R. Orbital apex syndrome. Curr Opin Ophthalmol. 2004;15(6):490-498.

2. Gilden D, Cohrs RJ, Mahalingam R, et al. Neurological disease produced by varicella zoster virus reactivation without rash. Curr Top Microbiol Immunol. 2010;342:243-253.

3. Womack LW, Liesegang TJ. Complications of herpes zoster ophthalmicus. Arch Ophthalmol. 1983;101(1):42-45.

4. Marsh RJ, Cooper M. Ophthalmic herpes zoster. Eye (Lond). 1993; 7(Pt 3):350-370.

5. Edgerton AE. Herpes zoster ophthalmicus: report of cases and a review of the literature. Trans Am Ophthalmol Soc. 1942;40:390-439.

6. Marsh RJ, Dulley B, Kelly V. External ocular motor palsies in ophthalmic zoster: a review. Br J Ophthalmol. 1977;61(11):677-682.

7. Shirato S, Oshitari T, Hanawa K, et al. Magnetic resonance imaging in case of cortical apex syndrome caused by varicella zoster virus. Open Ophthalmol J. 2008;2:109-111.

8. Kattah JC, Kennerdell JS. Orbital apex syndrome secondary to herpes zoster ophthalmicus. Am J Ophthalmol. 1978;85(3):378-382.

9. Dhingra S, Williams G, Pearson A. Severe permanent orbital disease in herpes zoster ophthalmicus. Orbit. 2008;27(4):325-327.

10. Krasnianski M, Sievert M, Bau V, et al. External ophthalmoplegia due to ocular myositis in a patient with ophthalmic herpes zoster. Neuromuscul Disord. 2004;14(7):438-441.

11. Bourke RD, Pyle J. Herpes zoster ophthalmicus and the orbital apex syndrome. Aust N Z J Ophthalmol. 1994;22(1):77-80.

12. Saxena R, Phuljhele S, Aalok L, et al. A rare case of orbital apex syndrome with herpes zoster ophthalmicus in a human immunodeficiency virus-positive patient. Indian J Ophthalmol. 2010;58(6):527-530. 
13. Sanjay S, Chan EW, Gopal L, et al. Complete unilateral ophthalmoplegia in herpes zoster ophthalmicus. J Neuroophthalmol. 2009;29(4): 325-337.

14. Lexa FJ, Galetta SL, Yousem DM, et al. Herpes zoster ophthalmicus with orbital pseudotumor syndrome complicated by optic nerve infarction and cerebral granulomatous angiitis: MR-pathologic correlation. AJNR Am J Neuroradiol. 1993;14(1):185-190.
15. Archambault P, Wise JS, Rosen J, et al. Herpes zoster ophthalmoplegia. Report of six cases. J Clin Neuroophthalmol. 1988;8(3):185-193.

16. Naumann G, Gass JD, Font RL. Histopathology of herpes zoster ophthalmicus. Am J Ophthalmol. 1968;65(4):533-541.

17. Greven CM, Ford J, Stanton C, et al. Progressive outer retinal necrosis secondary to varicella zoster virus in acquired immune deficiency syndrome. Retina. 1995;15(1):14-20.

\section{Publish your work in this journal}

Clinical Ophthalmology is an international, peer-reviewed journal covering all subspecialties within ophthalmology. Key topics include: Optometry; Visual science; Pharmacology and drug therapy in eye diseases; Basic Sciences; Primary and Secondary eye care; Patient Safety and Quality of Care Improvements. This journal is indexed on

\section{Dovepress}

PubMed Central and CAS, and is the official journal of The Society of Clinical Ophthalmology (SCO). The manuscript management system is completely online and includes a very quick and fair peer-review system, which is all easy to use. Visit http://www.dovepress.com/ testimonials.php to read real quotes from published authors. 